\title{
PELAYANAN KESEHATAN IBU DAN ANAK DI PUSKESMAS
}

\section{Aida Fitriani}

Fakultas Ilmu Sosial dan Ilmu Politik Universitas Kapuas Jln.Oevang Oeray Nomor: 92 Baning Kota Sintang

Email: aidafitriani45@gmail.com

\begin{abstract}
Abstrak:.Pelayanan Kesehatan Ibu dan Anak di Puskesmas Tanjung Puri dengan indikator sebagai berikut: 1). Jenis-jenis Pelayanan di Puskesmas Tanjung Puri Sintang menggunakan dua jenis pelayanan yaitu jenis pelayanan kesehatan didalam gedung Puskesmas dan jenis pelayanan kesehatan diluar gedung Puskesmas. 2). Standar Pelayanan Kesehatan Ibu dan Anak dilaksanakan sesuai dengan alur pelayanan kepada pasien yang terletak di dalam puskesmas lurus dengan pintu masuk, jadi pasien yang datang bisa langsung membaca dan mengetahui alur pelayanan. 3). Mekanisme Pelayanan di Puskesmas yaitu Pasien yang telah mendaftar menuju poli KIA/KB kemudian dilakukan pemeriksaan sesuai dengan keluhannya. Setelah dari poli Kesehatan Ibu dan Anak pasien dirujuk ke bagian lain sesuai dengan keluhannya. Pasien yang mendapatkan resep obat kemudian ke bagian apotek dan kasir untuk membayar, mengambil obat dan diperbolehkan pulang. 4). Sumber Daya Manusia berdasarkan jenis tenaga di Puskesmas tahun 2020 berjumlah 69 orang, 5). Sarana dan Prasarana merupakan suatu aspek terpenting dalam mencapai target dari program pelayanan kesehatan Puskesmas, sarana dan prasarana yang ada di Puskesmas sudah cukup memadai, baik berupa alat medis maupun obat-obatan.
\end{abstract}

Kata Kunci: Pelayanan Kesehatan, Ibu dan Anak, Puskesmas

Menurut Sinambela, (2011:3) Konsep Pelayanan Istilah pelayanan berasal dari kata "layan" yang artinya menolong menyediakan segala apa yang diperlukan oleh orang lain untuk perbuatan melayani. Pada dasarnya setiap manusia membutuhkan pelayanan, bahkan secara ekstrim dapat dikatakan bahwa pelayanan tidak dapat dipisahkan dengan kehidupan manusia. Pengertian pelayanan menurut Sinambela, (2011: 4) adalah "setiap kegiatan yang menguntungkan dalam suatu kumpulan atau kesatuan, dan menawarkan kepuasan meskipun hasilnya tidak terikat pada suatu produk secara fisik."

Saefullah (1999:7-8), membedakan lima jenis pelayanan umum, yaitu: Business service, menyangkut pelayanan dalam kegiatan-kegiatan konsultasi, keuangan dan perbankan; Trade service, kegiatan-kegiatan pelayanan dalam penjualan, perlengkapan, dan perbaikan; Infrastructur service, meliputi kegiatan-kegiatan pelayanan dalam komunikasi dan transportasi; Social and personal service, pelayanan yang diberikan antara lain dalam kegiatan rumah makan dan pemeliharaan kesehatan; dan Public administration, yang dimaksudkan disini adalah pelayanan dari pemerintah yang membantu kestabilan dan pertumbuhan ekonomi.
Menurut Saefullah (1999:8) menyimpulkan bahwa pada dasarnya secara garis besar pelayanan umum yang diberikan oleh pemerintah kepada masyarakat dapat dibedakan menjadi 2 (dua) kelompok besar, yaitu:Pertama, pelayanan umum yang diberikan tanpa memperhatikan orang perseorang, tetapi keperluan masyarakat secara umum. Dalam pelayanan ini meliputi penyediaan sarana dan prasarana transportasi, penyediaan pusatpusat kesehatan, pembangunan lembagalembaga pendidikan, pemeliharaan keamanan, dan lain sebagainya. Kedua, pelayanan yang diberikan secara orang perseorangan, pelayanan ini meliputi kemudahan-kemudahan dalam memperoleh pemeriksaan kesehatan, memasuki lembaga pendidikan, memperoleh kartu penduduk, pembelian karcis perjalanan dan sebagainya".

\section{Standar Pelayanan Kesehatan Ibu dan Anak}

Sutopo dan Sugiyanti (1998:67) menyatakan "standar pelayanan merupakan dokumentasi resmi yang berisi rincian teknis dari sebuah sistem pelayan". Standar pelayanan berguna sebagai pedoman kerja dari batasan mutu pelayanan yang harus dipenuhi oleh para pelaksana. Sedangkan bagi para pelanggan kita standar 
pelayanan berguna sebagai jaminan mutu pelayanan yang seharusnya mereka peroleh. Menurut Sutopo dan Sugiyanti (1998:67) "standar pelayanan umumnya memuat hal-hal seperti berikut: Visi dan Misi Pelayanan, Jenis Pelayanan yang ditawarkan, Spesifikasi Pelanggan, Prosedur Pelayanan, Pengawasan dan Pengendalian Mutu, Lampiran yang memuat Denah Lokasi, Formulir, Hasil Kesepakatan, dan sebagainya".

Sampai saat ini telah ditawarkan berbagai ukuran bagi standar pelayanan, dengan titik pusat penilaian yang saling berbeda, dan cara pengukuran yang beraneka ragam pula. Menurut Sutopo dan Sugiyanti (1998:36) namun demikian, terdapat beberapa kesamaan standar pelayanan yang sering dijumpai di berbagai bidang kajian, yaitu: Proses pelayanan dilaksanakan sesuai prosedur pelayanan yang standar. Petugas pelayanan memiliki kompetensi yang diperlukan. Pelaksanaan pelayanan didukung tekonologi, sarana, dan prasarana yang memadai. Pelayanan dilaksanakan dengan cara-cara yang tidak bertentangan dengan kode etik. Pelaksanaan pelayanan dapat memuaskan pelanggan. Pelaksanaan pelayanan dapat memuaskan petugas pelayanan. Pelaksanaan pelayanan mendatangkan keuntungan bagi lembaga penyedia pelayanan. Standar pelayanan merupakan aplikasi dari rancangan proses pelayanan dalam bentuk dokumentasi tertulis. Standar harus ditulis dengan cermat, rapi, dan menyeluruh. Bagi petugas pelayanan standar ini berlaku sebagai pedoman kerja dan baku mutu yang harus dipenuhi. Sedangkan bagi pelanggan standar ini memuat jaminan mutu pelayanan yang selayaknya akan mereka dapatkan.

\section{Mekanisme Pelayanan.}

Menurut Indrianto, (2008: 16) Ada 3 aspek yang harus diperhatikan dalam mekanisme pelayanan, yaitu: Tersedianya pelayanan. Mekanisme pelayanan tidak selalu tersedia untuk setiap saat. Misalnya dalam pertunjukan bioskop, loket penjualan karcis masuk hanya dibuka pada waktu tertentu antara satu pertunjukan dengan pertunjukan berikutnya. Sehingga pada saat loket di tutup, mekanisme pelayanan terhenti dan petugas pelayanan (pelayan) istirahat.

Kapasitas pelayanan. Kapasitas dari mekanisme pelayanan diukur berdasarkan jumlah langganan (satuan) yang dapat dilayani secara bersama - sama, kapasitas pelayanan tidak selalu sama untuk setiap saat; ada yang tetap, tapi juga ada yang berubah - ubah. Karena itu, fasilitas pelayanan dapat memiliki satu atau lebih saluran.
Fasilitas yang mempunyai satu saluran disebut saluran tunggal atau sistem pelayanan tunggal dan fasilitas yang mempunyai lebih dari satu saluran disebut saluran ganda atau pelayanan ganda. Lama berlangsungnya pelayanan. Lamanya pelayanan adalah waktu yang dibutuhkan untuk melayani seorang langganan atau satuan - satuan. Ini harus dinyatakan secara pasti. Oleh karena itu, waktu pelayanan boleh tetap dari waktu ke waktu untuk semua langganan atau boleh juga berupa variabel acak. Umumnya dan untuk keperluan analisis, waktu pelayanan dianggap sebagai variabel acak yang terpencar secara bebas dan sama tidak tergantung pada waktu pertibaan.

\section{Sumber Daya Manusia}

Menurut Moekijat (1987:3) mengemukakan bahwa ada tiga unsur kualitas yang perlu dikembangkan dari setiap pegawai yaitu: Keahlian, agar supaya pekerjaan dapat diselesaikan dengan lebih cepat dan lebih efektif. Pengetahuan, agar supaya pekerjaan dapat diselesaikan secara rasional. Sikap, agar supaya timbul kemauan kerja sama dengan teman-teman dengan pimpinannya. Pengembangan sumber daya manusia sangat penting kaitannya dengan menghilangkan kesenjangan antara kemampuan kerja dan tuntutan tugas serta untuk menghadapi tugas sekarang dan maupun untuk menjawab tantangan masa depan.

Osborne dan Gaebler, dalam Silalahi (1998:75), justru lebih mementingkan pengembangan visi dan misi aparat pemerintah dalam memberikan pelayanan kepada masyarakat / publik. Sejalan dengan semangat reformasi dan sistem desentralisasi, mereka lebih mengedepankan pengembangan sumber daya manusia pada visi, misi, inovasi dan kemampuan aparatur untuk melakukan semangat wirausaha dalam pelaksanaan tugas. Semangat ini merupakan semangat kerja yang lebih berorientasi menghasilkan daripada menghabiskan anggaran dan pada waktu yang sama kepentingan publik justru dapat ditingkatkan pelayanannya. Tujuan yang diharapkan dari adanya pengembangan sumber daya adalah untuk meningkatkan kemampuan teknis, teoritis, konseptual dan moral karyawan supaya prestasi kerjanya baik dan mencapai hasil yang optimal.

Manajemen Pegawai Negeri Sipil adalah keseluruhan upaya untuk meningkatkan efesiensi, efektivitas dan derajat profesionalisme penyelenggaraan tugas, fungsi dan kewajiban kepegawaian, yang meliputi perencanaan, pengadaan, pengembangan kualitas, penempatan, promosi, penggajian, kesejahteraan dan 
pemberhentian. Pegawai Negeri berkedudukan sebagai unsur aparatur negara yang bertugas untuk memberikan pelayanan kepada masyarakat secara profesional, jujur, adil dan merata dalam penyelenggaraan tugas negara, pemerintahan dan pembangunan. Konteks organsiasi pemerintahan, baik-buruknya mesin birokrasi sangat bergantung pada SDM aparatur di dalamnya sebagai aparatur penyelenggara pemerintah. Aparatur negara merupakan salah satu pilar dalam mewujudkan Good Governance bersama dengan dua pilar lainnya, yaitu dunia usaha (corporate governance) dan masyarakat (civil society). Ketiga unsur tersebut harus berjalan selaras dan serasi sesuai dengan peran dan tanggung jawab masing-masing. Sarana dan Prasarana

Sarana dan prasarana kerja dalam suatu kantor merupakan faktor pendukung dalam pelaksanaan kerja. Suwignyo (Robbins, 2000:190) mengemukakan bahwa: "keberhasilan suatu kegiatan sangat dipengaruhi oleh unsur-unsur pendukungnya yaitu mutu orang-orangnya serta sarana-sarana yang diperlukan". Sarana prasarana sebagai alat yang berfungsi mempercepat dan memperkuat organisasi mencapai tujuannya. Menurut Poerwadarminta (1984:29) "Fasilitas/ peralatan kerja merupakan barang yang dipakai untuk mengerjakan sesuatu, atau barang sesuatu yang dipakai untuk mencapai sesuatu maksud". Sedangkan menurut Kaho (2002:186) "peralatan adalah setiap benda atau alat yang dipergunakan untuk memperlancar atau mempermudah pekerjaan atau gerak aktivitas". Dari pengertian tersebut, dapat dipahami bahwa fasilitas/peralatan kerja merupakan barang, benda/alat yang dipergunakan untuk mempermudah atau memperlancar suatu aktivitas tertentu sehingga dapat mencapai tujuan yang dinginkan.

Menurut Kaho (2002:186) bahwa "jenis dari fasilitas/peralatan kerja menyangkut perangkat keras (hard ware) meliputi gedung, ruangan, peralatan perkantoran (mesin ketik/computer, kertas, meja, kursi, lemari), alat komunikasi, alat transportasi dan sebagainya". Ketersediaan fasilitas tersebut sangat penting dalam menunjang pelaksanaan tugas-tugas kantor. Dan menurut Kaho, (2002:187) bahwa "Fasilitas atau perlengkapan kerja dianggap baik memiliki beberapa kriteria yaitu cukup dalam jumlah, efisien, efektif serta praktis dalam penggunaannya".

Fasilitas/perlengkapan kerja dikatakan cukup dalam jumlah apabila peralatan yang tersedia sebanding atau seimbang dengan volume kerja yang ada, atau sebanding dengan jumlah tenaga yang akan menggunakannya, atau sebanding dengan kebutuhan dari organisasi. Peralatan dikatakan efesien jika output yang dikeluarkan haruslah maksimal sedangkan dari sudut input haruslah minimal. Suatu peralatan disebut efesien apabila penggunaannya tidak membuang-buang energi dan waktu dan tepat untuk suatu tujuan. Peralatan dianggap efektif apabila penggunaannya membawa efek (akibat, pengaruh, keadaan) seperti yang diharapkan. Atau dengan perkataan lain peralatan yang efektif adalah yang tepat dan mempercepat pencapaian tujuan.

\section{Metode}

Metode yang digunakan dalam penelitian adalah metode deskriptif kualitatif. Alasan pemilihan metode ini agar dapat mendapatkan jawaban yang lebih mendalam mengenai Pelayanan Kesehatan Ibu dan Anak di Puskesmas. Sumber data dalam peneltian ini adalah Kepala Puskesmas Tanjung Puri, Kepala Bagian Tata Usaha Puskesmas Tanjung Puri, Petugas pendaftaran Puskesmas Tanjung Puri Sintang, Petugas bagian pelayanan umum Puskesmas Tanjung Puri, Petugas bagian pelayanan KIA/KB Puskesmas Tanjung Puri, Pasien yang menerima pelayanan Kesehatan Ibu dan Anak. Teknik purposive digunakan untuk menetapkan Pasien yang menerima pelayanan Kesehatan Ibu dan Anak Informan dipilih secara purposive, yaitu dipilih dengan pertimbangan dan tujuan dimana peneliti ingin meneliti. Penentuan informan sumber data awal masih bersifat sementara dan berkembang kemudian setelah penulis di lapangan. Maka dalam penelitian ini informan yang dijadikan sumber data jumlahnya diketahui setelah penelitian selesai. Teknik pengumpulan data dalam penelitian ini adalah wawancara, Observasi, dan studi dokumentasi. Teknik analisis data bersifat kualitatif. Penelitian dilaksanakan di Puskesmas Tanjung Puri Kecamatan Sintang.

\section{Hasil Penelitian Dan Pembahasan}

Visi Puskesmas Tanjung Puri Sintang adalah "Kecamatan Sehat". Misi Puskesmas Tanjung Puri Sintang yaitu dalam upaya mewujudkan visi tersebut di atas, maka diterapkan misi Puskesmas Tanjung Puri Sintang adalah sebagai berikut: 1. Menggerakkan pembangunan berwawasan kesehatan. 2. Mendorong kemandirian masyarakat untuk hidup sehat. 3 . Memelihara dan meningkatkan pelayanan kesehatan individu, keluarga dan masyarakat yang bermutu, merata dan terjangkau. 4. Memelihara dan meningkatkan kesehatan individu, keluarga dan masyarakat beserta lingkungannya. 
Program Upaya Kesehatan Masyarakat, dengan kegiatan sebagai berikut: Kegiatan promosi kesehatan dan UKS termasuk PKPR, Kegiatan penyehatan lingkungan, Kegiatan KIA/KB masyarakat, Kegiatan peningkatan atau perbaikan gizi masyarakat, Kegiatan pencegahan dan pengendalian penyakit, Kegiatan keperawatan kesehatan masyarakat, Kegiatan kesehatan jiwa masyarakat, Kegiatan kesehatan gigi masyarakat, Kegiatan pembinaan kesehatan tradisional komplementer, Kegiatan kesehatan olahraga, Kegiatan kesehatan indera, Kegiatan kesehatan lansia dan Kegiatan kesehatan kerja. Program Upaya Kesehatan Perseorangan, dengan kegiatan: Kegiatan rawat jalan pemeriksaan umum, Kegiatan rawat jalan kesehatan gigi dan mulut, Kegiatan rawat jalan KIA-KB, Kegiatan penata laksanaan gawat darurat, Kegiatan penata laksanaan masalah gizi, Kegiatan pertolongan persalinan, Kegiatan penyediaan kefarmasian, Kegiatan penyediaan laboratorium, Kegiatan Klinik PKPR (Pelayanan Kesehatan Peduli Remaja). Program Upaya Keséhatan Rujukan yaitu Kegiatan pelayanan rujukan medik ke RSUD Ade M. Djoen untuk UKP, dan Kegiatan pelayanan rujukan kesahatan masyarakat ke Dinas Kesehatan Kabupaten Sintang untuk UKM.Puskesmas Tanjung Puri Sintang dibangun pada tahun 1998. Dalam rangka pemenuhan pelayanan kesehatan yang didasarkan pada kebutuhan dan kondisi masyarakat. Puskesmas Tanjung Puri Sintang dikategorikan berdasarkan karakteristik wilayah kerja termasuk Puskesmas Kawasan Perkotaan. Berdasarkan kemampuan penyelenggaraan pelayanan kesehatan, Puskesmas Tanjung Puri dikategorikan Puskesmas Non Rawat Inap.

Puskesmas Tanjung Puri mempunyai tugas melaksanakan kebijakan kesehatan untuk mencapai tujuan pembangunan kesehatan di wilayah kerjanya dalam rangka mendukung terwujudnya Kecamatan Sintang yang sehat dan Kabupaten Sintang umumnya. Dalam melaksanakan tugas sebagaimana dimaksud Puskesmas Tanjung Puri Sintang menyelenggarakan fungsi Penyelenggaraan UKM tingkat pertama di wilayah kerjanya. Kedudukan Puskesmas Tanjung Puri Sintang merupakan unit pelaksana teknis Dinas Kesehatan Kabupaten Sintang. Struktur Organisasi Puskesmas Tanjung Puri Sintang mengacu pada pola struktur organisasi Puskesmas kawasan perkotaan, yang terdiri dari:Kepala Puskesmas, Kasubag Tata Usaha, membawahi kegiatan: a). Sistem Infonnasi Puskesmas, b). Kepegawaian, c). Rumah tangga, dan d). Keuangan. Penanggungjawab UKM esensial dan keperawatan kesehatan masyarakat, membawahi: a). Pelayanan promosi kesehatan termasuk UKS, b). Pelayanan kesehatan lingkungan, c). Pelayanan KIA-KB yang bersifat UKM, d). Pelayanan gizi yang bersifat UKM, e). Pelayanan pencegahan dan pengendalian penyakit, f). Pelayanan keperawatan kesehatan masyarakat. Penanggungjawab UKM Pengembangan, membawahi: a). Pelayanan kesehatan jiwa, b). Pelayanan kesehatan gigi masyarakat, c). Pelayanan kesehatan tradisional komplementer, d). Pelayanan kesehatan olahraga, e). Pelayanan kesehatan indera, f). Pelayanan kesehatan lansia, dan g). Pelayanan kesehatan kerja.Penanggungjawab UKP, kefarmasian, dan laboratorium, membawahi: a). Pelayanan perneriksaan umum, b). Pelayanan kesehatan gigi dan mulut, c). Pelayanan KIA-KB yang bersifat UKP, d). Pelayanan gawat darurat, e). Pelayanan gizi yang bersifat UKP, f). Pelayanan persalinan, g). Pelayanan kefarmasian, dan h). Pelayanan laboratorium. Penanggungjawab jaringan pelayanan Puskesmas dan jejaring fasilitas pelayanan Kesehatan, membawahi: a). Puskesmas Pembantu, b). Puskesmas Keliling, c). Bidan Desa, d). Jejaring fasilitas pelayanan kesehatan.

\section{Pelayanan Kesehatan Ibu dan Anak di Puskesmas}

Puskesmas Tanjung Puri sebagai penyelenggara Pelayanan Kesehatan Ibu dan Anak yang mengutamakan upaya promotif dan preventif tanpa mengabaikan upaya kuratif dan rehabilitative kepada masyarakat mencakup perencanaan, pelaksanaan, evaluasi pencatatan, pelaporan, dan dituangkan suatu system informasi puskesmas yang menyediakan informasi untuk membantu pengambilan keputusan dalam melaksanakan manajemen puskesmas dalam mencapai sasaran kegiatan. Pelayanan di Puskesmas Tanjung Puri menuangkan informasi puskesmas dalam profil Puskesmas Tanjung Puri Sintang tahun 2020 yang diharapkan bisa digunakan sebagai laporan hasil kegiatan tahun 2020 dan dasar perencanaan kegiatan Puskesmas Tanjung Puri Sintang tahun 2021 yang diharapkan dapat mewujudkan masyarakat yang: a). Memiliki perilaku sehat yang meliputi kesadaran, kemauan dan kemampuan hidup sehat, b). Mampu menjangkau pelayanan kesehatan yang bermutu, c). Hidup dalam lingkungan sehat, dan d). Memiliki derajat kesehatan yang optimal, baik individu, keluarga, kelompok dan masyarakat.

\section{Jenis-jenis Pelayanan}

Puskesmas Tanjung Puri menggunakan dua jenis pelayanan. Puskesmas Tanjung Puri dalam memberikan pelayanan kesehatan yaitu jenis 
pelayanan kesehatan didalam gedung Puskesmas Tanjung Puri dan jenis pelayanan kesehatan diluar gedung Puskesmas Tanjung Puri. a). Pelayanan kesehatan di dalam gedung terdiri dari: 1). Tindakan medis/keperawatan. 2). Pemeriksaan umum, 3). Kesehatan anak, 4). Kesehatan gigi dan mulut, 5). Kesehatan ibu dan anak (KIA), Keluarga Berencana dan Imunisasi, 6). Gizi, 7). Kesehatan Lingkungan, 8). Jiwa, 9). Laboratorium, 10). Klinik IMS/IVA/ Cryotherapy, 11). Klinik remaja sehat remaja hebat, 12). Klinik Lansia/PROLANIS, 13). Stimulasi, Intervensi, dan Deteksi Tumbuh Kembang, 14). Klinik Akupresur, dan 15). Ruang Farmasi/ Pelayanan Obat. b). Pelayanan kesehatan di luar gedung terdiri dari:1). Posyandu Bayi Balita, 2). Posyandu Lansia, 3). Pusling, 4). Pelayanan kesehatan warga binaan, 5). Pembinaan UKS/ UKGS, 6). Penjaringan Kesehatan bagi anak sekolah, 7). Pemberantasan Jentik Nyamuk, dan 8). Penyelidikan Epidemiologi.

Selain dua jenis pelayanan kesehatan tersebut di atas, jenis-jenis pelayanan kesehatan ibu dan anak di Puskesmas Tanjung Puri Sintang terdiri dari: a). Pemeriksaan ibu hamil, b). Pelayanan persalinan, c). Imunisasi, d). Konseling gizi kesehatan ibu dan anak, e). Pemeriksaan calon pengantin, f). Kunjungan rumah kesehatan ibu dan anak, g). Pelayanan keluarga berencana, h). Pelayanan keluarga berencana post plasenta (on call), i). Kelas air susu ibu, j). Pelayanan USG ibu hamil, k).Pelayanan kesehatan peduli remaja.

\section{Standar Pelayanan Kesehatan Ibu dan Anak di Puskesmas}

Kegiatan pelayanan merupakan suatu usaha untuk membantu menyiapkan atau mengurusi apa yang diperlukan masyarakat yang ditujukan dalam upaya meningkatan kesejahteraan masyarakat. Pelayanan pada sektor kesehatan merupakan salah satu bentuk kegiatan nyata untuk meningkatkan kesejahteraan masyarakat. Puskesmas Tanjung Puri sebagai lembaga kesehatan milik pemerintah untuk melaksanakan pelayanannya berpedoman pada standar pelayanan menurut Keputusan Menteri Pendayagunaan Aparatur Negara No.63/KEP/M.PAN/7/2003 mengenai prosedur pelayanan, waktu penyelesaian, biaya pelayanan, produk pelayanan, sarana dan prasarana, serta kompetensi petugas pemberi pelayanan. Mengacu pada keputusan Menteri Pendayagunaan Aparatur Negara tersebut, berikut data hasil penelitian masing - masing standar pelayanan. Prosedur pelayanan merupakan tahapan kegiatan yang dilakukan dalam proses penyelesaian pelayanan yang dilakukan bagi pemberi dan penerima pelayanan termasuk pengaduan.

Prosedur pelayanan di Puskesmas Tanjung Puri dilaksanakan sesuai dengan alur pelayanan kepada pasien yang terletak di dalam puskesmas lurus dengan pintu masuk, jadi pasien yang datang bisa langsung membaca dan mengetahui alur pelayanan di Puskesmas Tanjung Puri. Secara umum alur pelayanan di Puskesmas Tanjung Puri dimulai dari pasien datang kemudian ke bagian pendaftaran untuk mengambil nomor antrian. Pasien yang telah mendapatkan nomor antrian menunggu dipanggil sesuai nomor antrian yang didapatkan, kemudian setelah dipanggil, pasien masuk ke ruangan poli/bagian pelayanan yang dituju guna melakukan pemeriksaan. Setelah pasien selesai diperiksa kemudian dokter memberikan diagnosa kepada pasien untuk selanjutnya mendapatkan rujukan atau hanya mendapat obat jalan. Pasien kemudian ke bagian kasir untuk melakukan pembayaran. Pasien yang telah membayar biaya pelayanan dan obat, dapat mengambil obat di bagian obat dan pasien boleh pulang.

Prosedur pelayanan di Puskesmas Tanjung Puri juga terbagi dalam setiap bagian yaitu, prosedur pelayanan bagian pendaftaran, prosedur pelayanan BP Umum, prosedur pelayanan KIA/KB, prosedur pelayanan caten (calon penganten), prosedur pelayanan konsultasi psikologi. Prosedur pendaftaran di Puskesmas Tanjung Puri Sintang yaitu Pasien datang mengambil nomor antrian dan dipersilahkan duduk, setelah itu mengisi form pendaftaran dan menunjukkan kartu identitas serta kartu jaminan kesehatan. Pasien dibagi menjadi tiga bagian yaitu pasien baru, pasien lama, dan pasien lebih dari satu poli. Petugas membuatkan kartu pendaftaran untuk pasien baru, kemudian pasien mendapatkan kartu tunggu poli. Petugas langsung memberikan kartu tunggu poli untuk pasien lama, dan pasien lebih dari satu poli, petugas memberikan nomor antrian poli lebih dari satu dan memberikan nomor rekam medis sesuai poli yang dituju. Petugas kemudian mempersilahkan pasien duduk dan menunggu di depan poli yang dituju.

Prosedur pelayanan BP umum yaitu dimulai dari pasien yang menunggu di ruang tunggu menyiapkan nomor antrian, kartu identitas dan kartu jaminan kesehatan. Pasien masuk BP umum menuju ruang perawat untuk memberikan tanda tangan di lembar registrasi, menyampaikan keluhan, melakukan pengukuran (tensi, suhu, tinggi badan,berat badan) kemudian menunggu panggilan 
dokter. Pasien yang telah dipanggil oleh Dokter masuk ke ruang Dokter dan dilakukan pemeriksaan, kemudian mendapatkan resep obat atau rujukan ke bagian lain dan rujukan ke Rumah sakit. Pasien yang tidak perlu dirujuk setelah mendapatkan resep obat dapat langsung menuju ruang administrasi dan ruang obat. Pasien yang perlu rujukan dirujuk ke bagian/poli yang lain yang berada di Puskesmas dan menuju ke bagian/poli terkait untuk pemeriksaan lebih lanjut. Pasien yang perlu dirujuk ke rumah sakit menuju ke bagian pendaftaran untuk mendapat nomor rujukan. Setelah semua selesai barulah pasien yang mendapat rujukan menuju kasir untuk urusan administrasi dan pengambilan obat.

Pegawai di Puskesmas Tanjung Puri bertugas menyelenggarakan upaya kesehatan pertama yang ada didesa yang bersifat menyeluruh, terpadu, merata, dapat di terima dan terjangkau oleh masyarakat dengan menitik beratkan kepada pelayanan untuk masyarakat luas guna mencapai derajat kesehatan yang optimal, tanpa mengabaikan kualitas dan mutu pelayanan kepada perorangan. Untuk teknisnya Puskesmas Tanjung Puri dalam melayani pasiennya mempuyai SOP (Standart Operating Procedure).

Bagi pasien yang pertama kali datang diberikan nomor antrian lalu juga kartu pasien untuk mengetahui riwayat keluhan apa saja yang telah dialami para pasien setelah itu pasien yang tidak memiliki Jamkesmas, BPJS dan lainnya dikenakan biaya hanya untuk menebus obat dan pemeriksaan yang dilakukan dokter dibagian administrasi setelah selesai mengurus administrasinya para pasien langsung masuk dikamar penanganan atau pemeriksaan yang ditangani dokter dan perawat dan selanjutnya setelah selesai proses penanganan yang diberikan pasien akan diberikan obat yang sesuai dengan keluhan para pasien-pasien ini. Prosedur yang diberikan puskesmas ini dirasa tidak memberikan kesulitan untuk para pasien sehingga para pasien tidak mengalami kesulitan ketika baru berkunjung untuk memeriksakan kesehatannya.

Sebagian masyarakat mengetahui Standar Pelayanan Kesehatan Ibu dan Anak di Puskesmas Tanjung Puri. Karena pelayanan yang diberikan Puskesmas Tanjung Puri Sintang dari segi tangible (bukti fisik) yang terlihat sudah mengikuti SOP (Standart Operating Procedure). Selanjutnya petugas bagian pelayanan Kesehatan Ibu dan Anak/ Keluarga Berencana menambahkan bahwa Standar Pelayanan Kesehatan Ibu dan Anak di Puskesmas Tanjung Puri Sintang yang diberikan sudah mengikuti SOP (Standart Operating Procedure).
Standar Pelayanan Kesehatan Ibu dan Anak di Puskesmas Tanjung Puri sudah sesuai harapan masyarakat. Terbukti dengan memberikan pelayanan sesuai dengan yang dijanjikan secara akurat dan terpercaya. Kinerja pegawai Puskesmas Tanjung Puri Sintang sesuai dengan harapan masyarakat yang berarti ketepatan waktu, pelayanan yang sama untuk semua pasien tanpa kesalahan, sikap yang simpatik dan dengan akurasi yang tinggi. Selain dari pada itu pegawai Puskesmas Tanjung Puri bekerja mengikuti SOP (Standart Operating Procedure) dan menjalankan tugas sesuai bagiannya masing-masing.

\section{Mekanisme Pelayanan.}

Mekanisme Pelayanan Kesehatan Ibu dan Anak di Puskesmas Tanjung Puri meliputi prosedur pelayanan poli Kesehatan Ibu dan Anak/Keluarga Berencana, dimulai dari Ibu hamil atau pasien yang melakukan pendaftaran di loket pendaftaran. Pasien yang telah mendaftar menuju poli Kesehatan Ibu dan Anak / Keluarga Berencana kemudian dilakukan pemeriksaan sesuai dengan keluhannya. Setelah dari poli Kesehatan Ibu dan Anak pasien dirujuk ke bagian lain sesuai dengan keluhannya. Pasien yang mendapatkan resep obat kemudian ke bagian apotek dan kasir untuk membayar, mengambil obat dan diperbolehkan pulang. Mekanisme Pelayanan Kesehatan Ibu dan Anak di Puskesmas Tanjung Puri tersebut sudah memuaskan. Terbukti para pegawainya sudah siap dan berada di tempat kerjanya sesuai bagiannya dan sesuai jam kerja. Para pegawai tersebut menyambut dan mengarahkan pasien sesuai prosedur dan bagiannya masing-masing.

Sikap pegawai dalam memberikan pelayanan kepada pasien di Puskesmas Tanjung Puri yaitu perawat dan bidan dalam memberikan pelayanan kepada pasien cukup memuaskan dan mudah dalam pengurusan administrasinya, tidak ribet". Kemudian pelayanan dalam pengurusan administrasi, dalam artian tanpa hambatan yang berjalan sebagaimana mestinya dapat mengubah persepsi masyarakat menganggap bahwa birokrasi yang terlalu rumit mampu merubah kesan jelek tersebut di masyarakat. Untuk urusan administrasi yang terlihat cukup baik tidak banyak membuat para pasien kebingungan, para petugas puskesmas pembantu memang harus bisa diandalkan dalam setiap pelayanannya guna tercapainya pelayanan yang memuaskan bagi para pasiennya. Pelayanan Kesehatan Ibu dan Anak di Puskesmas Tanjung Puri yang diberikan pegawai Puskesmas sudah sesuai dengan prosedur karena terbukti pada waktu 
melayani pasien, perawat dan bidan mengikuti SOP (Standart Operating Procedure) dan menjalankan tugas sesuai bagiannya masing-masing. Pelayanan Kesehatan Ibu dan Anak di Puskesmas Tanjung Puri yang diberikan pegawai Puskesmas sudah sesuai dengan prosedur karena terbukti pada waktu melayani pasien, perawat dan bidan menjalankan tugasnya sesuai bidangnya.

Pegawai selalu cepat dalam menangani atau menanggapi keluhan pasien dan tepat dalam mengidentikasi setiap keluhan penyakit para pasien namun dari segi kecepatan terkadang para petugas sedikit lambat dalam menangani ini dikarenakan fasilitas dan jumlah para petugas yang dimiliki puskesmas ini harus menjadi evaluasi untuk meningkatkan pelayanannya khususnya dari segi kecepatan. Pengetahuan, kesopansantunan dan kemampuan para dokter dan perawat puskesmas Tanjung Puri menumbuhkan rasa percaya para pasien. Hal ini meliputi beberapa komponen antara lain komunikasi (communication), kredibilitas (credibility), keamanan (security), kompetensi (competence), dan sopan santun (courtesy). Jaminan mempunyai indikator : a. Kesopanan petugas dalam memberikan pelayanan $b$. Kesanggupan petugas dalam menangani keluhan pelanggan c. Kemampuan petugas dalam memberikan rasa aman atau kepercayaan waktu menghadapi pasien d. Kejujuran petugas dalam memberikan pelayanan.

\section{Sumber Daya Manusia}

Sumber daya manusia berdasarkan jenis tenaga di Puskesmas Tanjung Puri tahun 2020 berjumlah 69 orang yang terdiri dari Dokter Umum berjumlah 7 orang, Dokter Gigi berjumlah 3 orang, Perawat berjumlah 27 orang, Bidan berjumlah 8 orang, Tenaga Kesehatan Masyarakat berjumlah 2 orang, Tenaga Kesehatan Lingkungan berjumlah 2 orang, Ahli Teknologi Laboratorium Medik berjumlah 2 orang, Tenaga Gizi berjumlah 2 orang, Tenaga Kefarmasian berjumlah 1 orang, Tenaga Administrasi berjumlah 3 orang, Pekarya berjumlah 3 orang, Asisten Apoteker berjumlah 3 orang, Perawat Gigi berjumlah 3 orang, Akutansi berjumlah 1 orang, Tenaga Struktural berjumlah 2 orang.

Jumlah sumber daya manusia di Puskesmas Tanjung Puri sudah sesuai dengan kebutuhan. Hal ini terlihat bawasannya sumber daya manusia di Puskesmas Tanjung Puri Sintang sudah menjalankan tugas pokok dan fungsinya dalam hal melayani pasien yang berobat di PuskesmasTanjung Puri. Sumber daya manusia (SDM) yang merupakan kunci penggerak organisasi. Pelaksanaan pelayanan di Puskesmas Tanjung Puri untuk melakukan kinerja yang baik perlu adanya evaluasi yang sebagaimana dengan ketentuan yang berlaku. Dalam melaksanakan tugas sebagaimana dimaksud mempunyai rumusan dan pelaksanaan kebijakan penyusunan program kerja dan koordinasi teknis dengan satuan tugas pegawai Puskesmas Tanjung Puri. Tugas dan tanggung jawab pegawai Puskesmas Tanjung Puri adalah memberikan pelayanan kesehatan kepada masyarakat. Untuk dapat meningkatkan kualitas pelayanan kesehatan masyarakat diperlukan peningkatan kualitas pegawai. Sumber Daya Manusia yang ada mampu menggerakkan pegawai dengan baik dan melakukan tugas pokok secara efektif dan efisien. Sumber Daya Manusia yang berkualitas tidaklah cukup untuk menjalankan organisasi jangka panjang. Diperlukan loyalitas pegawai terhadap organisasi tempat bekerja. Dengan membangun hubungan emosional antara organisasi dan pegawainya maka seorang pegawai di Puskesmas Tanjung Puri berusaha semaksimal mungkin memberikan kontribusi terbaik buat masyarakat.

Tanpa adanya hubungan emosional antara organisasi dan pegawai maka pegawai di Puskesmas Tanjung Puri hanya menjalankan kewajibannya tanpa memberikan seluruh kemampuannya untuk berorganisasi. Bila kewajibannya telah dilakukan maka dia hanya akan berjalan ditempat tanpa memberikan inovasi, kreatifitas, dan ide cemerlang yang sebenarnya bisa dilakukan bila pegawai Puskesmas Tanjung Puri memiliki ikatan emosional membuat ingin membangun dan mengembangkan organisasi yang lebih baik. Keterampilan pegawai dalam pelaksanaan tugas pokok dan fungsinya yang berkaitan sumber daya manusia telah mengikuti kursus pelatihan di Rumah Sakit Umum. Keikutsertaan kursus pelatihan di Rumah Sakit Umum yang berguna untuk mendapatkan suatu pengalaman dalam peningkatan kinerja pegawai Puskesmas Tanjung Puri. Pegawai yang ada di Puskesmas Tanjung Puri sudah menjalankan tupoksinya yang berkaitan dengan sumber daya manusia. Pada aspek pengalaman dan pengetahuan pekerjaan, apabila dikaitkan dengan kematangan pekerjaan menyangkut sejauh mana kemampuan yang dimiliki oleh seseorang sesuai dengan tugastugas yang menjadi tanggung jawab dalam melayani kesehatan masyarakat.

\section{Sarana dan prasarana.}

Sarana dan prasarana merupakan suatu aspek terpenting dalam mencapai target dari program-program pelayanan kesehatan Puskesmas 
Tanjung Puri. Sarana dan prasarana yang ada di dalam Puskesmas Tanjung Puri sudah cukup memuaskan, baik berupa alat medis maupun obatobatan. Hal ini terjadi dari sumber anggaran yang dimiliki Puskesmas Tanjung Puri dikelola sesuai peraturan pemerintah untuk mutu pelayanan puskesmas Tanjung Puri yang menjadi nyaman karena sudah lengkap sesuai kebutuhan masyarakat dengan standart kesehatan. Sarana dan prasarana Puskesmas Tanjung Puri sudah lengkap sesuai dengan kebutuhan pegawai.Hal ini terbukti dengan adanya jumlah tenaga medis yang cukup mengakibatkan kemampuannya melaksanakan program dari Dinas Kesehatan. Misalnya program Posyandu yang tepat sasaran dan didukung sarana dan prasarana yang lengkap karena Puskesmas Tanjung Puri terletak di dekat Kota, dan juga sumber keuangan Puskesmas Tanjung Puri dari pemerintah pusat maupun daerah yang didapat sebanding dengan pengeluaran operasional Puskesmas. Adapun sumber-sumber keuangan Puskesmas Tanjung Puri biaya berasal dari Pemerintah Kabupaten Sintang yang dibedakan atas dana pembangunan dan dana anggaran rutin. Dana ini diturunkan secara bertahap ke Puskesmas melalui Dinas Kesehatan Kabupaten. Ruang laboratorium fasilitasnya sesuai dengan standar minimal, sudah ada pembatas ruangan selain itu alat- alatnya juga sudah lengkap".sarana dan prasarana dalam hal ini meliputi gedung dan sarana fisik yang memadai, peralatan medis yang sesuai dengan standar puskesmas dan peralatan perlengkapan kantor yang memadai. Puskesmas Tanjung Puri memiliki sarana dan prasarana dalam mendukung pelaksanaan pelayanannya, dan kelengkapan sarana dan prasarana yang dimiliki masih layak digunakan dan dalam kondisi baik.

Prasarana adalah segala sesuatu yang merupakan penunjang utama terselenggaranya suatu proses. Berdasarkan observasi, prasarana yang dimiliki Puskesmas Tanjung Puri meliputi: a). Gedung Puskesmas dengan lantai seluruhnya keramik dengan dinding berlapis semen. Kondisinya masih bagus, gedung masih tampak baru dan rapi dengan tiap-tiap ruangan di dalamnya. b). Ruang tunggu yang relatif luas, terdiri dari 10 kursi panjang, dan tempat bermain anak. c) Ruang pelayanan terdiri dari ruang Laboratorium, ruang tindakan, ruang laktasi, ruang gizi, ruang BP Umum, ruang BP Gigi, ruang KIA, ruang imunisasi, ruang $\mathrm{KB}$, ruang pendaftaran, ruang kasir, ruang apotek, dan ruang konsultasi psikologi. d). Ruang lainnya selain ruang tunggu dan ruang pelayanan meliputi, ruang kepala Puskesmas, ruang tata usaha, aula, ruang manajemen representative, ruang ukm, gudang obat, Mushola, gudang, dapur, dan toilet. e). Tempat parkir puskesmas sebagai instansi pelayanan masyarakat dalam setiap harinya menerima pasien dalam jumlah banyak. Tidak sedikit pasien membawa menggunakan kendaraan pribadi untuk sampai ke Puskesmas.Keberadaaan tempat parkir perlu diperhatikan sebagai penunjang kepuasan pasien.

Selain prasarana di atas ada juga jenis rincian kelengkapan sarana yang dimiliki Puskesmas Tanjung Puri dalam menunjang proses pelayanan pada tabeldi bawah ini,

Tabel 1 Jenis rincian kelengkapan sarana yang dimiliki Puskesmas Tanjung Puri ta

\begin{tabular}{|c|c|c|c|c|}
\hline No & Perlengkapan & Jumlah Aset & Satuan & Keterangan \\
\hline 1 & Mobil Puskesmas Keliling & 2 & Unit & Baik \\
\hline 2 & Sepeda motor Dinas & 9 & Unit & Baik \\
\hline 3 & Almari es/Cold chain & 4 & Buah & Baik \\
\hline 4 & IUD kit & 2 & Buah & Baik \\
\hline 5 & Dopler & 1 & Buah & Baik \\
\hline 6 & Tensi meter & 28 & Buah & Baik \\
\hline 7 & Stetoskop & 15 & Buah & Baik \\
\hline 8 & Timbangan dacin & 17 & Buah & Baik \\
\hline 9 & Timbangan bayi & 8 & Buah & Baik \\
\hline 10 & Mesin ketik & 4 & Buah & Baik \\
\hline 11 & Komputer & 11 & Buah & Baik \\
\hline 12 & Tabung oxygen 2 buah & 2 & Buah & Baik \\
\hline 13 & Kursi roda & 2 & Buah & Baik \\
\hline 14 & Sterilisator listrik & 1 & Buah & Baik \\
\hline 15 & Genset & 2 & Buah & Baik \\
\hline 16 & Dental unit & 2 & Buah & Baik \\
\hline 17 & Kompresor & 2 & Buah & Baik \\
\hline 18 & Lampu operasi & 2 & Buah & Baik \\
\hline 19 & Ugd set & 1 & Set & Baik \\
\hline 20 & PHN kit & 2 & Set & Baik \\
\hline 21 & Elektrokardiograf & 1 & Buah & Baik \\
\hline 22 & Otoskop & 1 & Buah & Baik \\
\hline 23 & Mikroskop & 2 & Buah & Baik \\
\hline 24 & Hematokrit & 1 & Buah & Baik \\
\hline 25 & Certifuge & 1 & Set & Baik \\
\hline 26 & Urine meter & 1 & Buah & Baik \\
\hline 27 & Glukomenmeter & 1 & Buah & Baik \\
\hline 28 & Tabung LPG 1 buah & 1 & Buah & Baik \\
\hline
\end{tabular}

Sumber data: Puskesmas Tanjung Puri tahun 2020. 


\section{Kesimpulan dan Saran}

Jenis-jenis Pelayanan di Puskesmas Tanjung Puri menggunakan dua jenis pelayanan yaitu jenis pelayanan kesehatan didalam gedung Puskesmas Tanjung Puri dan jenis pelayanan kesehatan diluar gedung Puskesmas Tanjung Puri. Standar Pelayanan Kesehatan Ibu dan Anak dilaksanakan sesuai dengan alur pelayanan kepada pasien yang terletak di dalam puskesmas lurus dengan pintu masuk, jadi pasien yang datang bisa langsung membaca dan mengetahui alur pelayanan di Puskesmas Tanjung Puri. Mekanisme Pelayanan di Puskesmas Tanjung Puri yaitu prosedur pelayanan poli Kesehatan Ibu dan Anak/Keluarga Berencana, dimulai dari Ibu hamil atau pasien yang melakukan pendaftaran di loket pendaftaran. Pasien yang telah mendaftar menuju poli Kesehatan Ibu dan Anak/Keluarga Berencana kemudian dilakukan pemeriksaan sesuai dengan keluhannya. Setelah dari poli Kesehatan Ibu dan Anak pasien dirujuk ke bagian lain sesuai dengan keluhannya. Pasien yang mendapatkan resep obat kemudian ke bagian apotek dan kasir untuk membayar, mengambil obat dan diperbolehkan pulang. Sumber Daya Manusia berdasarkan jenis tenaga di Puskesmas Tanjung Puri Sintang tahun 2020 berjumlah 69 orang. Sarana dan Prasarana merupakan suatu aspek terpenting dalam mencapai target dari program pelayanan kesehatan Puskesmas Tanjung Puri. Sarana dan prasarana yang ada di dalam Puskesmas Tanjung Puri sudah cukup memadai, baik berupa alat medis maupun obat-obatan.

Diharapkan Puskesmas Tanjung Puri meningkatkan sumber daya manusia dengan rasa tanggung jawab pegawai.,mengembangkan kemampuan sumber daya manusia dibidang kesehatan lingkungan dan tingkat puskesmas, membuat brosur/buku tentang prosedur layanan kesehatan dan perlunya dukungan pemerintah daerah terkait kebijakan-kebijakan dibidang pelayanan kesehatan puskesmas.

\section{DAFTAR PUSTAKA}

Arikunto, S. 1998. Prosedur Penelitian Suatu Pendekatan Praktek. Jakarta: Rinneka Cipta.

Indrianto. 2008. Model Pelayanan Profesional Jakarta. Balitbang Puskur.

Kaho, J.R. 2002. Prospek Otonomi Daerah di Negara Republik Indonesia: Idetifikasi Beberapa Faktor Yang $M e r m p \quad e \quad n \quad g$ a $r$ u $h \quad i$ Penyeleng garaannya. Jakarta:Rajawali Perss.

Poerwadarminta.1984.Kamus Umum Bahasa Indonesia, Jakarta. PN Balai. Pustaka.

Robbins. 2000. Perilaku Organisasi. PT. Prenhallindo. Jakarta.

Saefullah, 1999. Konsep dan Metode Pelayanan Umum yang Baik, dalam. Jurnal Ilmu Sosial dan Ilmu Politik. Sumedang: Fisip UNPAD.

Silalahi, Ulbert .1998. Studi Tentang Ilmu Administrasi Konsep, Teori dan Dimensi,. CV Sinar Baru, Bandung.

Sinambela. P.L, dkk. 2011. Reformasi Pelayanan Publik Teori, Kebijakan, Implementasi. Jakarta: Bumi Aksara.

Sutopo dan Sugiyanti. 1998. Pelayanan Prima. Jakarta: LAN. 